\section{ORTHODONTIC ASSESSMENT GOES DIGITAL}

Plaster study models will no longer be accepted when submitting completed orthodontic cases to NHS Dental Services. Instead, 3D digital study models must be submitted. These may be produced by scanning impressions, cast models or by intra-oral scanning but must be in STL file format.

Routine clinical orthodontic monitoring is performed by NHS Dental Services' team of independent specialist orthodontic advisers, usually conducted remotely as a desktop exercise.

Each performer can expect to have a minimum of five completed cases assessed on a three-year rolling cycle. More frequent assessment is arranged if concerns are identified or at the request of the local commissioners.

Orthodontic case assessment forms should be submitted to NHS Dental Services with the following items for each of the five selected cases: all relevant radiographs; copies of intra-oral photographs (where available); a FP17 DC0 form; laboratory dockets; and 3D digital study models of the pre- and post-treatment dentition and occlusion for each of the five selected cases.

NHS Dental Services advises that assistance with production of 3D digital images from original plaster study models may be obtained from your local laboratory, and also provides advice and suggests three suppliers at the following link: www.nhsbsa.nhs.uk/ DentalServices/4445.aspx.

\title{
BOLTON PRACTICE OPENS ON UNIVERSITY CAMPUS
}

A new practice was opened on the University of Bolton campus by Chief Dental Officer Barry Cockcroft CBE on 24 March 2014.

Thought to be the first of its kind in the country, the practice unites the University of Bolton with dentists Mark Ray and Irfan Ravat. The collaboration aims to bring new services and new academic courses to the town centre campus.

The state-of-the-art practice is based in the health, leisure and research centre Bolton One, and will offer full dental services.

Mark Ray, partner of Ravat and Ray, said: 'We are delighted to be working alongside the university, who have great foresight and drive to develop accessible learning and development for all:

Later this year Bolton will launch professional development and postgraduate dental courses with employer input and support from Ravat and Ray.

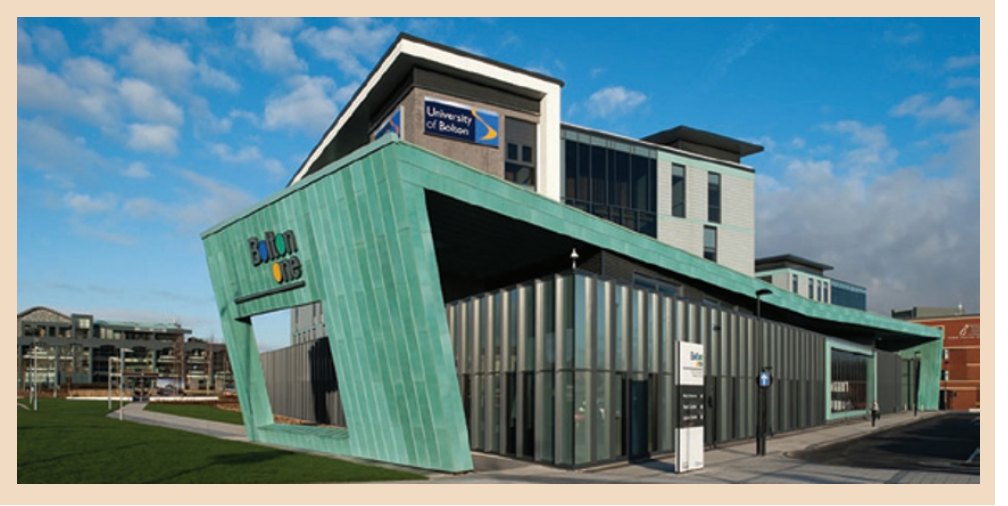

